\title{
Erratum to: Observed variations in stratification and currents in the Zuari estuary, west coast of India
}

D. Sundar ${ }^{1}$ • A. S. Unnikrishnan ${ }^{1}$ - G. S. Michael ${ }^{1}$ - A. Kankonkar ${ }^{1}$

A. G. Nidheesh ${ }^{1} \cdot$ M. P. Subeesh ${ }^{1}$

Published online: 24 July 2015

(c) Springer-Verlag Berlin Heidelberg 2015

\section{Erratum to: Environ Earth Sci}

DOI 10.1007/s12665-015-4702-2

The original article has been published inadvertently with some errors in the Fig. 8. The tidal curves of frames (c) and (d) of Fig. 8 were interchanged by mistake. The corrected figure is given below:

The online version of the original article can be found under doi:10.1007/s12665-015-4702-2.

\section{Sundar}

sundar@nio.org

1 CSIR-National Institute of Oceanography,

Dona Paula 403004, Goa, India 
Fig. 8 Variation of stratification parameter $(\Delta S)$ in Zuari estuary over a tidal cycle during spring-neap phases of the three seasonal cycles. $D, C$, $B$ and $S$ indicate Dona Paula, Cortalim, Borim and

Sanvordem locations shown at their respective distances from the mouth in the $Y$ axis.

Corresponding tide variation is given in each diagram. Grey area shows no data. The Selaulim dam discharge rates are negligible during pre monsoon. The discharge rates in units of $\mathrm{m}^{3} / \mathrm{s}$ were 84.48 and 85.90 on 1 and 2 August, 61.07 and 50.61 on 9 and 10 August, 11.50 and 11.20 on 23 and 24 October and 10.62 and 10.60 on 29 and 30 October, respectively
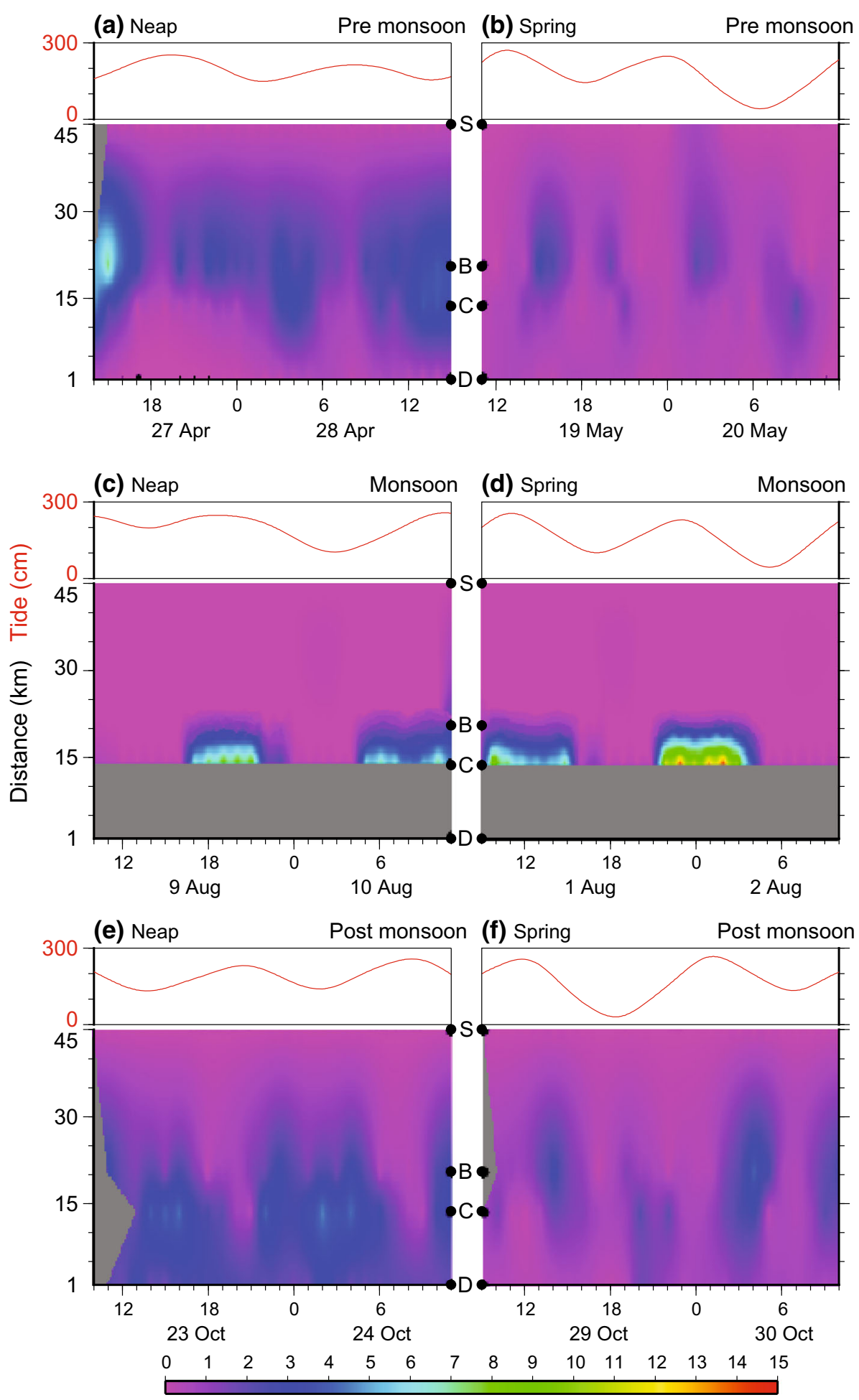

Stratification Parameter $(\Delta \mathrm{S})$ 